\title{
Artigo \\ Influência do tempo de recozimento sobre a recristralização e tenacidade ao impacto de um aço baixo carbono.
}

\author{
Dyana Alves de Oliveira [1], Francisco Edson Nogueira Fraga [2] \\ [1] Universidade Federal Rural do Semi-árido; dyanaalvesoliveira@gmail.com

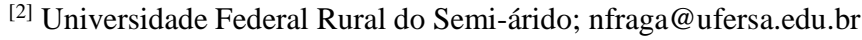 \\ Recebido: 07/06/2019; \\ Aceito: 09/08/2019; \\ Publicado: 07/10/2019.
}

Resumo: Nesse trabalho foi avaliada a influência do tempo de tratamento térmico sobre a microestrutura e propriedades mecânicas de uma barra chata encruada de aço baixo carbono. As amostras foram submetidas ao tratamento térmico de recozimento, a $900{ }^{\circ} \mathrm{C}$, em períodos distintos, de uma hora, duas horas e três horas. As mudanças microestruturais foram analisadas através de microscopia óptica, as alterações na dureza e tenacidade do aço foram medidas através de ensaios mecânicos de dureza e Charpy respectivamente. Os resultados dos ensaios mecânicos mostram redução na dureza em função do aumento de tempo recozimento e também diminuição da tenacidade ao impacto. Essas alterações nas propriedades mecânicas mensuradas foram atribuídas, ambas, ao crescimento de grão em função do tempo de tratamento térmico de recozimento. Complementarmente, as seções fraturadas dos corpos de prova Charpy foram analisadas por microscopia eletrônica de varredura - MEV. Observou-se que a amostra encruada, que tem menor tamanho de grão em relação as outras, apresentou fratura frágil; enquanto as amostras que passaram por tratamento térmico apresentaram fratura dúctil-frágil.

Palavras-chave: Aço baixo carbono; tenacidade ao impacto; dureza; tamanho de grão; fratura frágil.

\section{INTRODUÇÃO}

$\mathrm{D}$ urante décadas, vem-se utilizando da técnica de laminação - a frio ou a quente - para as mais diversas aplicações na indústria, uma delas é a confecção de barras chatas de aço. Nesse processo, ocorrerão algumas mudanças microestruturais, tais como a mudança das propriedades morfológicas do grão, bem como a mudança em sua orientação, agora adquirindo uma orientação preferencial, a fração volumétrica de área dos contornos de grão aumentará, assim como aumentarão os defeitos puntiformes e discordâncias por unidade de volume. Esses últimos servem como barreira para conter a propagação de deslizamentos de discordâncias ou outros defeitos. A laminação gera tensões internas devido as distorções promovidas na rede cristalina do material. Com isso, obtêm-se uma elevação nos valores de dureza, ocasionada pela interação entre os planos de deslizamento e os contornos de grão. Em contrapartida, o material perderá parte de sua ductilidade e capacidade de absorção de energia por impacto. Durante esse processo, devido o atrito entre a superfície da peça e os cilindros de laminação, parte da energia será dissipada na forma de calor [13,20-21].

O material encruado possuirá uma dureza mais elevada, que, para algumas aplicações na indústria não é desejável. Em decorrência disso, utilizam-se tratamentos térmicos para diminuir a dureza do material, como o recozimento. Esse tratamento diminuirá a energia de deformação armazenada, de modo que ocorrerá um rearranjo em sua microestrutura, bem como a eliminação dos defeitos cristalinos. Além disso, haverá uma melhoria na usinabilidade do material. Também ocorrerá a recristalização e ajustes no tamanho de grão, que, dependendo do tempo e temperatura a qual o material será submetido, poderá ocorrer o crescimento de grão, etc. $[13,20]$.

O crescimento de grão promove um aumento na tenacidade do material, entretanto, ela é fortemente influenciada por fatores morfológicos dos grãos. Assim, quando o material for submetido a cargas externas, 
poderá apresentar fraturas do tipo dúctil ou frágil. Na fratura frágil, a energia necessária para propagar a trinca é geralmente baixa. Já na fratura dúctil, ocorre uma apreciável deformação plástica antes e durante a propagação da trinca. Esse último tipo de fratura absorve grande parte da energia necessária para movimentar e multiplicar as discordâncias no material. Os concentradores de tensão fazem com que a tenacidade do componente seja reduzida, mesmo com mecanismo de fratura dúctil [10-11,16].

O presente artigo tem por objetivo analisar a influência do tempo de tratamento térmico de recozimento sobre a microestrutura, dureza e tenacidade. Bem como, observar qual o tipo de fratura que o material apresenta quando submetido ao tratamento térmico de recozimento pleno em períodos distintos. Para o tal, fez-se o uso de um aço baixo carbono laminado, hipoeutetóide, adquirido no mercado local e posteriormente submetido a tratamentos térmicos de recozimento.

\subsection{Aço Carbono}

Nos aços, o teor de carbono presente em sua estrutura cristalina limita-se até $2,11 \%$ p. A dissolução do carbono no ferro em temperatura ambiente é relativamente baixa, de modo que com o aumento da temperatura, mais carbono poderá ser dissolvido, pois a estrutura cristalina do ferro, em determinada temperatura, passa de CCC (ferro $\alpha$ - fase ferrita) para CFC (ferro $\gamma$ - fase austenita). Os aços com teores de carbono até $0,77 \%$ p, são denominados hipoeutetóides [7].

Ao se adicionar átomos de soluto no aço, no caso o carbono, promove-se uma alteração nas propriedades mecânicas, como o aumento da resistência e da dureza. Essa adição de soluto também facilitará as transformações de fase quando o aço for submetido a tratamentos térmicos [10].

Os contornos de grão funcionam como barreiras para impedir o movimento das discordâncias ou outros defeitos cristalinos. "Os átomos de soluto têm mais influência na resistência de atrito para o movimento das discordâncias" [10]. Os átomos de soluto segregam-se em contornos de grão, falhas de empilhamento, discordâncias, etc. Quanto mais átomos de soluto forem adicionados, maior será a tensão de escoamento [10].

“Os limites entre os grãos num agregado policristalino constituem-se em regiões cristalinas perturbadas de somente alguns diâmetros atômicos de magnitude radial” [10]. Desse modo, cada grão possuirá uma direção cristalina diferente daqueles outros de baixo ângulo (ou subcontornos) [10,20] .

\subsection{Tratamento Térmico de Recozimento}

Os tratamentos térmicos têm por objetivo a realização de mudanças na microestrutura e nas propriedades mecânicas dos materiais. A maioria dos tratamentos para aços consiste em aquecer o produto até determinada temperatura para que ocorra a austinetização do produto por completo. O fator principal, que caracterizará cada tratamento, em sua maioria, será a taxa de resfriamento e em que meio o material será resfriado, pois através dessa taxa podemos determinar a fase que o material apresentará ao final do tratamento [7-8,20].

"O recozimento visa reduzir a dureza do aço, aumentar a usinabilidade, facilitar o trabalho a frio ou atingir a microestrutura ou as propriedades desejadas" [20]. Quanto maior a energia térmica absorvida pela amostra durante o recozimento, mais significativa será a redução da microdureza e da resistência do material. Isso ocorre porque quando se aumenta a temperatura do aço, suas moléculas ficarão excitadas dando início aos processos de recuperação e recristalização do material. Com o passar do tempo, a energia contida nos contornos de grão poderá atuar como potencial termodinâmico para que ocorra o crescimento dos grãos. Assim, o aumento do tempo de recozimento em conjunto com a elevação da temperatura, diminui o tempo de recristalização do aço e a fração de volume da amostra recristalizada [1,9,13,19-20]. Logo, os grãos de ferrita que antes estavam alongados, devido a laminação, tornam-se grãos equiaxiais durante a recristalização, bem como a fração dessa fase aumenta [14].

O tratamento térmico de recozimento pode se classificar em:

Recozimento pleno: o aço é aquecido $50{ }^{\circ} \mathrm{C}$ acima do limite superior da zona crítica. Para o caso dos aços hipoeutetóides, esse aquecimento ocorre acima da linha A_3. O produto desse tratamento é um aço com microestrutura com ferrita e perlita. Quanto maior for a temperatura de austenitização, durante um determinado tempo, mais homogênea será a microestrutura, no caso perlítica. Para austenitização em temperaturas mais baixas, a microestrutura será mais heterogênea, a qual favorecerá a nucleação ou crescimento de carbonetos não dissolvidos em regiões com mais teor de carbono. De modo que em algumas regiões a fase cementita estará mais presente $[7-8,20]$. 
Recozimento subcrítico: seu principal objetivo é recuperar a ductilidade que foi perdida durante o processo mecânico de trabalho a frio. Esse tratamento promove a recuperação e recristalização da fase encruada. Em geral, sua faixa de aquecimento é abaixo da zona crítica, entre 600 e $680^{\circ} \mathrm{C}$, seguida de resfriamento em ar [78,20]. "O aumento de temperatura nestes tratamentos é suficiente para reduzir o limite de escoamento do material ou permitir a deformação por fluência, de modo que as tensões residuais são aliviadas através da deformação plástica" [20].

Esferoidização: seu principal objetivo é melhorar a usinabilidade dos aços através da formação de uma microestrutura globular. É feito através de aquecimento acima ou abaixo da zona crítica, e logo em seguida resfriamento. Podendo ocorrer aquecimento e resfriamento alternados [7-8,20].

Recozimento em caixa: consiste em aquecer o aço, geralmente entre 600 a $700{ }^{\circ} \mathrm{C}$, para que não ocorra a oxidação da superfície em decorrência do contato com o meio ao qual estaria sendo exposto. Utiliza-se grandes lotes de peça $[7-8,20]$.

\subsection{Encruamento}

Ao se promover uma deformação plástica em um metal, ocorrerá uma variação em seu volume. Essa deformação pode ocorrer através de difusão, maclação mecânica, transformações de fase ou através da movimentação de discordâncias, sendo esta última a que mais contribui para que ocorra o aumento da energia interna do material. Em alguns policristais, essa deformação pode ocorrer em decorrência da movimentação dos contornos de grão por fluência [15].

Grande parte da energia introduzida através desse processo é dissipada em forma de calor, e a outra parte será armazenada no material em forma de defeitos cristalinos. Em um policristal, ocorrerão algumas mudanças tais como: uma alteração na orientação dos grãos, os quais tenderão a orientar-se em uma direção preferencial; haverá uma mudança nos formatos dos grãos, a quantidade de áreas de contorno de grão por unidade de volume, bem como a quantidade de defeitos puntiformes e discordâncias por unidade de volume aumentará [15].

"A densidade e distribuição de defeitos gerados na deformação plástica dependem de fatores tais como: estrutura cristalina do metal; temperatura, quantidade e velocidade de deformação; pureza do metal e sua energia de defeito por empilhamento" [15].

A área dos contornos de grão por unidade de volume aumentará, devido a deformação promovida ao material. Com isso, aumenta-se também a área de contato com os defeitos, como as discordâncias, cuja movimentação será restringida, aumentando a dureza. A morfologia dos grãos será alterada, de modo que os mesmos ficarão mais alongados $[10,13,20]$.

\subsection{Recuperação, Recristalização, Nucleação e Crescimento de Grão}

Na recuperação ocorre uma restauração parcial das propriedades mecânicas do material, as quais foram modificadas durante algum processo de deformação. Com isso, ocorre a aniquilação dos interstícios e lacunas presentes no material, bem como a aniquilação e rearranjo de discordâncias com sinais opostos. Também ocorrerá uma migração de defeitos puntiformes e das discordâncias na direção dos contornos de grão, assim como haverá a formação de subgrãos. Ocorrerá uma diminuição da energia interna proveniente dos defeitos presentes no material $[6,15]$.

A recristalização trata-se de um processo no qual haverá uma transformação de fase por meio da nucleação e crescimento de grão. Ocorre uma diminuição da energia armazenada, decorrente de um processo de deformação, bem como haverá um rearranjo e eliminação de defeitos cristalinos, e ocorrerão mudanças na microestrutura do material. "Acredita-se que os átomos de impurezas segregam-se preferencialmente para, e interagem com esses contornos de grão recristalizados, de forma a diminuir suas mobilidades (isto é, dos contornos de grão), isso resulta em uma diminuição na taxa de recristalização e aumenta a temperatura de recristalização" [6]. O aumento da temperatura de recozimento diminui o tempo de recristalização $[6,15]$.

A nucleação é caracterizada por ser o início do processo de recristalização. Os núcleos formados são regiões isentas de defeitos, devido o rearranjo de discordâncias e outros defeitos. Assim, essa região possui uma baixa densidade de defeitos cristalinos. Os núcleos passam a existir no processo de deformação, o qual fará com que o material se apresente em seu estado encruado, com algumas regiões heterogêneas, as quais favorecerão a formação de bandas de transição e cisalhamento, locais propícios para a formação de pré-núcleos, regiões com altas diferenças de orientação [6,15].

O crescimento de grão ocorre após o término do processo de recristalização. De modo que, esse crescimento pode ocorrer de forma contínua, havendo um aumento contínuo do tamanho médio do grão, e de 
forma descontínua, havendo um crescimento acentuado apenas em alguns grãos. O crescimento dos grãos irá promover uma diminuição da área dos contornos por unidade de volume, e os contornos migrarão no sentido oposto ao seu centro de curvatura na recristalização. A curvatura desses contornos promove uma diferença de potencial química, favorecendo o deslocamento dos átomos através dos contornos de grão. Logo, alguns grãos ficarão maiores que outros devido a migração desses átomos de um grão para outro [6,15].

Então, quanto maior o tempo que a amostra permanecer na temperatura escolhida para o tratamento térmico, maior será o tamanho do grão. Um tempo demasiadamente longo poderá promover oxidação ou descarbonetação no material. E, quanto menor a temperatura para promover a austenização, a austenita será mais heterogênea, favorecendo a nucleação de carbonetos em regiões onde se tem uma maior concentração de átomos de carbono, assim como pode promover o crescimento dos carbonetos dissolvidos presentes no material. Inicialmente esses carbonetos não serão distribuídos uniformemente, e ao decorrer do tratamento se alinharão na direção de laminação. Quanto maior o tamanho do grão, maiores serão as chances do grão apresentar uma maior quantidade de carbono em seu interior. Entretanto, se os grãos forem pequenos, os átomos de carbono, bem como os carbonetos, tenderão a segregarem-se nos contornos de grão [6-7,13,15,20].

\subsection{Fratura}

"Fratura é a separação ou fragmentação de um corpo sólido em duas ou mais partes, sob a ação de uma tensão" [10]. A fratura é gerada através da formação de trincas, as quais serão propagadas ao longo do material. Existem dois principais tipos de fratura: dúctil e frágil [10].

A fratura dúctil é caracterizada por apresentar uma apreciável deformação antes de sua ruptura, quando o material for submetido a uma tensão. A deformação do material é iniciada por um empescoçamento. A princípio, ocorre formação de pequenas cavidades esféricas e microvazios, os quais aumentarão de tamanho até a formação de uma trinca que se propagará ao longo material até que ocorra a sua ruptura [6,10]. "A região interna central da superfície tem uma aparência irregular fibrosa" [6] característica de fraturas dúcteis.

A fratura frágil é caracterizada por ter uma rápida propagação de trinca sem nenhuma deformação macroscópica e nenhuma deformação microscópica apreciável. A propagação da trica é aproximadamente perpendicular à direção de aplicação de uma tensão. As trincas podem se propagar através dos grãos, denominando-se fratura transgranular, e podem se propagar ao longo dos contornos de grão, denominando-se fratura granular $[6,10]$.

Todo material apresenta um comportamento característico quando é submetido a tensões, de forma que poderá apresentar uma zona elástica, onde toda a deformação promovida será revertida, ou não. Ao término da região elástica, o material começa a se deformar plasticamente, de modo que em uma determinada tensão aplicada ocorrerá o rompimento. Quando esse material possui defeitos ou trincas microscópicas, em sua superfície ou em seu interior, a tensão aplicada será amplificada ou concentrada nas regiões que possuem esses defeitos [6,10]. “A amplificação da tensão não está restrita a esses defeitos microscópicos; ela também pode ocorrer em descontinuidades internas macroscópicas (por exemplo, vazios ou inclusões), em arestas vivas, arranhões e entalhes" [6].

\section{MATERIAIS E MÉTODOS}

O material utilizado nesse trabalho foi uma barra chata laminada de aço carbono SAE 1020 com dimensões de 3" x 1/2", obtidas no comércio local. Dessa barra, obteve-se quatro amostras, das quais três foram recozidas a $900^{\circ} \mathrm{C}$ em períodos distintos, uma hora, duas horas e três horas. Em seguida, as amostras foram resfriadas em ar calmo. Foi utilizada a norma da ASTM E23-02 para a realização do ensaio Charpy.

Avaliou-se quatro condições: material encruado e à temperatura ambiente; material recozido durante uma hora e à temperatura ambiente; material recozido durante duas horas e à temperatura ambiente; material recozido durante três horas e à temperatura ambiente. Foram confeccionados cinco corpos de prova para cada condição, totalizando vinte corpos de prova.

Os ensaios de impacto foram realizados em uma máquina de ensaio Charpy do fabricante Time Group INC®. modelo JB-W300A, utilizando um martelo pendular de $300 \mathrm{~J}$, com o corpo de prova em apoio simples.

Foram analisadas as imagens da fratura dos corpos de prova do ensaio de impacto, através do Microscópio Eletrônico de Varredura VEGA® 3LMU.

As amostras foram preparadas metalograficamente de maneira convencional. Foram lixadas e em seguida foram polidas com alumina. Realizou-se o ataque químico com nital à $2 \%$ por 10 segundos. As imagens de 
microestrutura foram obtidas em um microscópio óptico e lentes ópticas do fabricante Olympus Corporation ${ }^{\circledR}$, modelo GX51 e SC30 respectivamente.

A partir das imagens obtidas no microscópio óptico, foi determinado o tamanho de grão de acordo com a norma ASTM E112-13, em função dos tempos de tratamento térmico, bem como constatação do material em estudo. Para isso, foi utilizado o software AutoCAD® (licença para estudante). A imagem foi exportada em sua escala para o programa, e utilizou-se o comando "circle" para desenhar um círculo na imagem, em conformidade com as dimensões estipuladas em norma e de acordo com a escala da imagem. A contagem dos grãos foi feita manualmente.

Os ensaios de dureza foram realizados no durômetro Mitutoyo® HR-300. Foram realizadas quinze medições de dureza para cada amostra, de acordo com a norma ASTM E18-19.

\section{RESULTADOS E DISCUSSÃO}

\subsection{Microestruturas}

Foram obtidas imagens no microscópio óptico das quatro amostras, para se fazer a análise da microestrutura do material. A partir delas, observou-se as mudanças na morfologia dos grãos para relacionar com as mudanças nas propriedades mecânicas do material. Obteve-se o tamanho de grão de cada amostra, como pode ser observado na Tabela 1.

A microestrutura do aço apresentou mudanças quando foi submetido a um tratamento térmico de recozimento pleno. De modo que a microestrutura resultante desse processo é ferrita e perlita, pois o resfriamento promovido nesse tratamento é lento, favorecendo assim a sua formação.

Inicialmente, como observado na micrografia da Figura 1 a), o aço está em seu estado encruado, apresentando grãos alongados e menores devido seu processo de fabricação. Com a promoção do tratamento térmico, a microestrutura será recristalizada. De modo que com uma hora de tratamento, os grãos de ferrita aumentaram, tornando-se ligeiramente esferoidizados, Figura 1 b). Com duas e três horas de tratamento, os grãos de perlita começaram a aumentar de tamanho devido a migração dos átomos de carbono, e foi distribuída de forma mais homogênea ao longo do material, Figuras 1 c) e d). As amostras reagiram de modo semelhante à observada em outro estudo [12], no qual a microestrutura se apresentou homogênea em toda a região, com redução dos grãos de perlita, que se apresentaram parcialmente de forma esferoidizada, e um aumento dos grãos de ferrita.
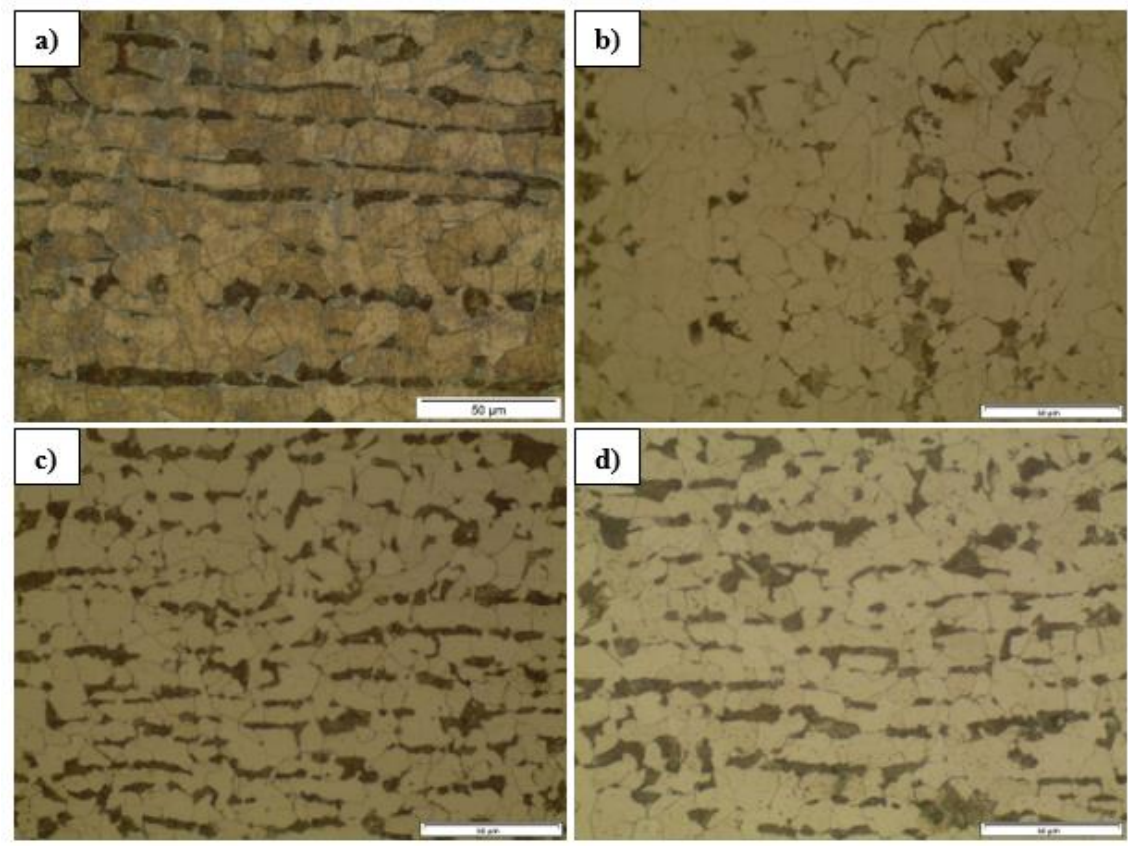

FIGURA 1. Fotomicrografias, com aumento de 500x, das amostras: a) encruada, b), c) e d) recozidas respectivamente por 1 hora, 2 horas e 3 horas. (Autoria própria) 


\subsection{Ensaios de Dureza}

A tabela a seguir mostram os valores obtidos nos ensaios mecânicos e na análise microestrutural das quatro amostras.

TABELA 1. Valores das propriedades mecânicas e do tamanho de grão do aço SAE 1020 (Autoria própria)

\begin{tabular}{cccc}
\hline Amostra & Dureza $($ HRB $)$ & Energia de Impacto $(J)$ & Tamanho de Grão $(\mu \mathrm{m})$ \\
\hline Encruada & $76,17 \pm 1,41$ & $56 \pm 10,5$ & $12,78 \pm 0,91$ \\
Recozida 1h & $72,74 \pm 1,15$ & $105 \pm 4,4$ & $14,60 \pm 1,30$ \\
Recozida 2h & $72,26 \pm 0,31$ & $112 \pm 2,8$ & $15,25 \pm 1,13$ \\
Recozida 3h & $70,96 \pm 0,80$ & $200 \pm 7,9$ & $16,65 \pm 1,30$ \\
\hline
\end{tabular}

De acordo com os dados apresentados na Tabela 1, os valores de dureza diminuem com o tempo de recozimento. De modo que, quando o aço está na condição de encruado, sua dureza possui um valor de 76,17 $\mathrm{HRB}$, enquanto com uma hora de recozimento seu valor diminui para 72,74 HRB, com duas horas para 72,26 HRB e com três horas para 70,96 HRB. Isso ocorre porque durante o recozimento, ocorre a recristalização do material e posteriormente o crescimento de grãos. Esse crescimento de grãos, faz com que ocorra redução de dureza do material. Pois, o material apresentará uma menor área de contornos de grão por unidade de volume, diminuindo assim a área na qual as discordâncias serão retidas.

Observando a micrografia, Figura 1, podemos notar que com uma hora de recozimento se promoveu o crescimento dos grãos de ferrita, e nota-se uma heterogeneidade na distribuição dos grãos de perlita ao longo da peça. Isso ocorreu porque quando se promove a deformação no aço, tanto os carbonetos quanto as fases contendo carbono em sua composição são distribuídas de acordo com a direção de laminação. Com duas horas de recozimento ocorreu uma homogeneização na microestrutura, de forma que os grãos de perlita aumentaram seu tamanho, devido a migração dos átomos de carbono de um grão para o outro, e foram distribuídos de forma uniforme ao longo da peça. A perlita é uma fase bastante dúctil e apresenta índices de durezas bem inferiores a outras fases, como bainita, martensita e cementita. Com três horas ocorreu o crescimento dos grãos de perlita, o que faz com que a dureza diminua ainda mais.

As amostras reagiram de maneira semelhante à observada em outro estudo [18], onde a dureza do material diminuiu com o tratamento térmico de recozimento, devido um aumento no tamanho de grão de ferrita, a qual tem dureza inferior à perlita.

\subsection{Ensaios de Impacto Charpy}

Observando a Tabela 1, podemos notar que o recozimento promoveu ao material um aumento da sua tenacidade ao impacto. Quanto maior o tempo de permanência do material a temperatura de $900^{\circ} \mathrm{C}$, maior será o tamanho de grão do material. De forma que, o crescimento dos grãos, promoveram um aumento na ductilidade do material. Logo, o material necessitou absorver uma maior quantidade de energia (ao impacto) para fraturar. Consequentemente, maior foi a deformação promovida antes da ruptura, em decorrência do aumento da ductilidade. A energia de impacto absorvida pelo material foi dissipada, podendo ter se apresentado tanto em forma de calor quanto na forma de deformação plástica, esta última foi promovida ao material até a sua ruptura.

A Figura 2 apresenta os valores das médias e desvios padrões da tenacidade ao impacto, obtidas durante o ensaio Charpy, em função dos tempos de tratamento térmico de recozimento das amostras. A Figura 2 foi elaborada com o intuito de facilitar a visualização dos dados apresentados na Tabela 1. 


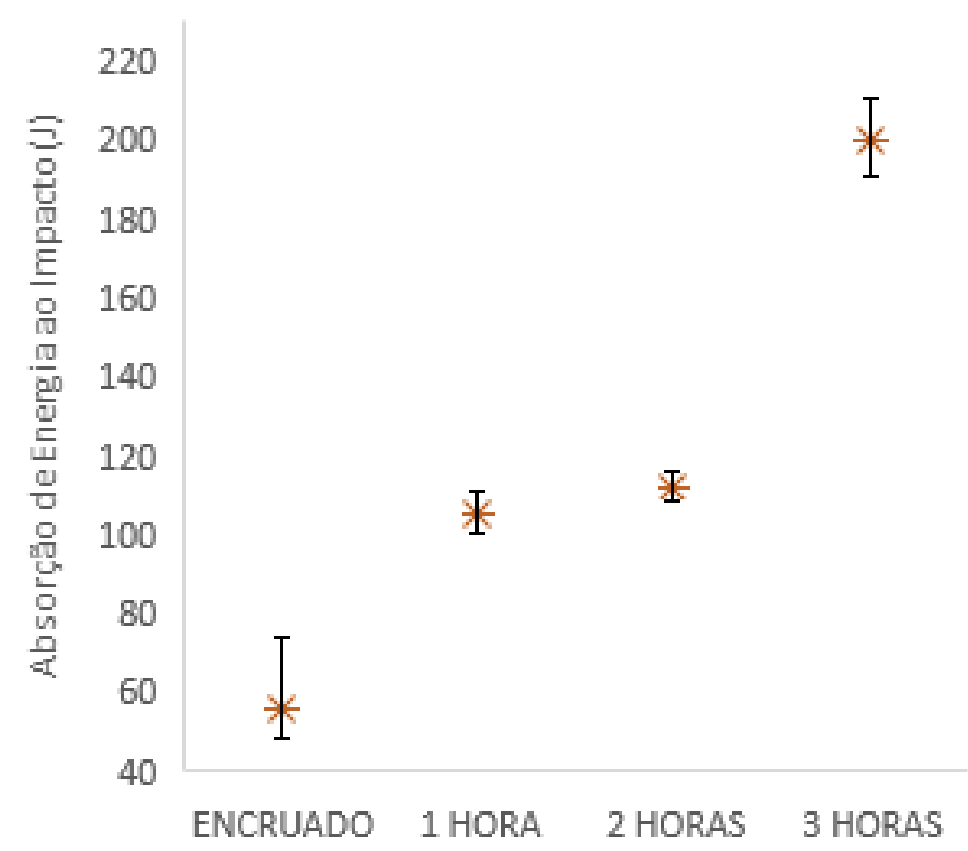

FIGURA 2. Gráfico das médias e desvios padrões da tenacidade ao impacto das amostras: encruada e recozidas durante uma hora, duas horas e três horas. (Autoria própria)

Como pode ser observado na Tabela 1, ocorreu a alteração do tamanho de grão em função do tempo de tratamento térmico, de 11,78 $\mu \mathrm{m}$ para $16,65 \mu \mathrm{m}$. Comparando os dados da Tabela 1 com a Figura 2, observouse que ocorreu um aumento significativo na absorção de energia ao impacto entre o material encruado e o material recozido durante uma hora. Em contrapartida, entre uma hora e duas horas não houve um aumento considerável na absorção de energia, assim como em seu tamanho de grão. Entre duas e três horas de recozimento, ocorreu um aumento na absorção de energia ao impacto. Provavelmente o grão recristalizou, e em seguida ocorreu o seu crescimento. Entretanto, essa alteração no tamanho de grão, em função do tempo de tratamento térmico, não foi suficiente para caracterizar um crescimento de grão acentuado a ponto de comprometer a tenacidade ao impacto

As amostras reagiram de maneira semelhante à observada em outro estudo [16] no qual realizou-se o mesmo ensaio com uma máquina de ensaio Charpy, modelo JB-W300 A, usando um martelo pendular de 300 (J), com o corpo de prova em apoio simples com as medidas segundo a norma ASTM E23-94a e mostrou que o material aumentou sua capacidade de absorção de energia ao impacto com o tratamento térmico de recozimento.

\subsection{Microscopia Eletrônica de Varredura}

Foram obtidas imagens no Microscópio Eletrônico de Varredura (MEV) das quatro amostras, para se fazer a análise da fratura do material, ocasionada no ensaio de impacto. A partir delas, é possível analisar com precisão o tipo de fratura do material, e por qual mecanismo a fratura se propagou. 

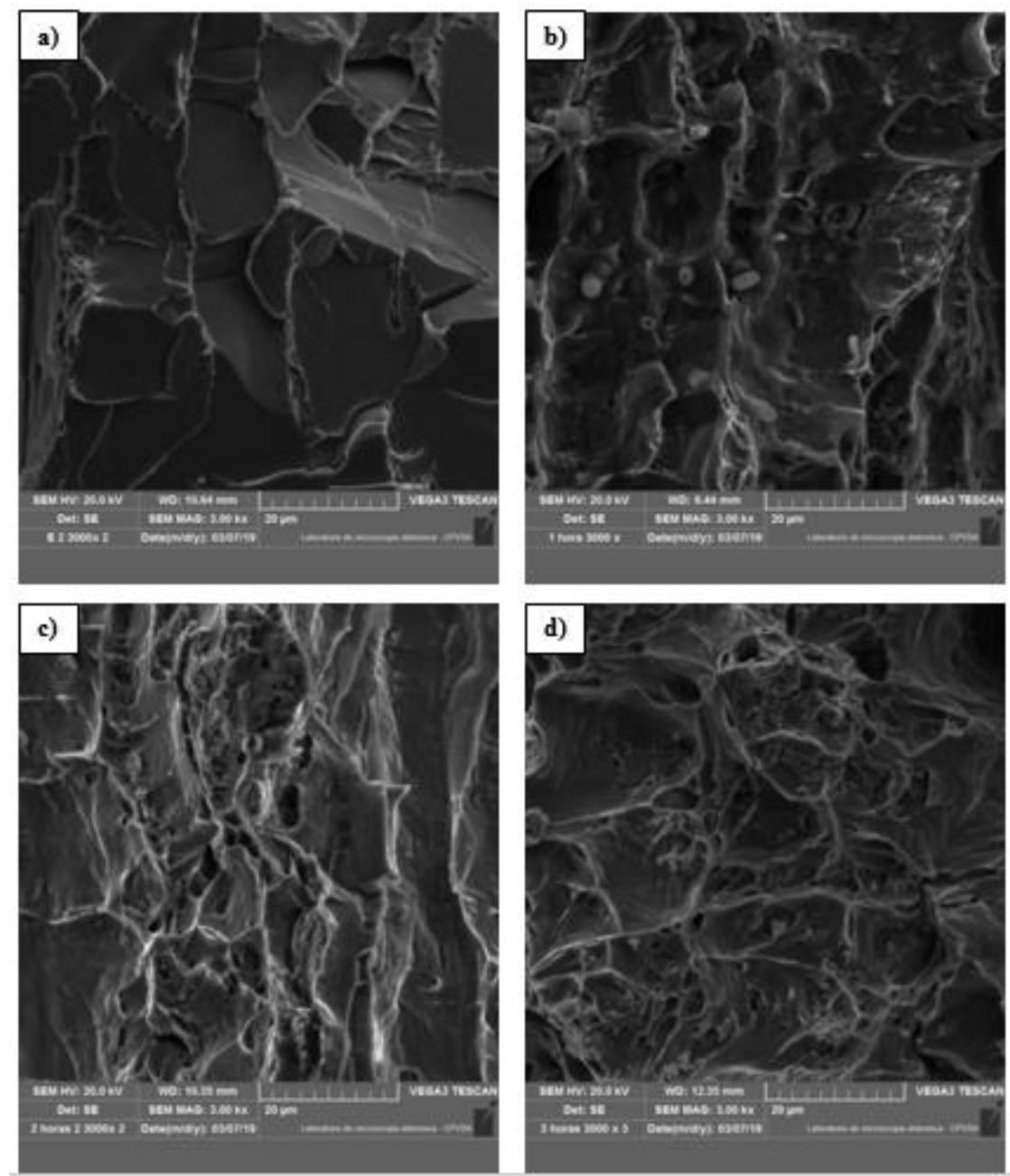

FIGURA 3. Fractografia obtidas no Microscópio Eletrônico de Varredura, com aumento de 3000x, das amostras: a) encruada, b), c) e d) recozidas respectivamente por 1 hora, 2 horas e 3 horas. (Autoria própria)

A fratura na Figura 3 a) ocorreu de forma frágil, ou seja, não ocorreu uma deformação plástica significativa. O material é caracterizado por apresentar facetas de clivagem com numerosos platôs, com alto grau de perfeição geométrica e refletividade, bem como "marcas de rios" em decorrência do crescimento das trincas em dois ou mais planos cristalográficos paralelos. Além do mecanismo de fratura por clivagem, o material apresentou o mecanismo de fratura intergranular.

Nas Figura 3 b), c) e d), que foram tratadas termicamente, apresentaram fratura dúctil-frágil. Observou-se um aumento na ductilidade do material, que também pode ser observado na Tabela 1 com o aumento da capacidade de absorção de energia de impacto. De forma que, a microestrutura de ferrita com uma pequena quantidade de perlita, que foi obtida, favoreceu o aparecimento de vazios, o que leva a obtenção de uma microcavidade mais profunda na região fraturada. Essas microcavidades apresentam-se na forma de vazios (dimples) de aspecto equiaxial. Logo, quanto maior o tempo de recozimento, maior será a capacidade do material sofrer deformação plástica, assim como maior será o gasto energético para romper o material, como podemos observar na Tabela 1.

As amostras reagiram de maneira semelhante à observada em outro estudo [18] no qual as amostras foram submetidas ao ensaio Charpy, e foi avaliado o tipo de fratura no qual o material apresentou. Analisou-se que com o aumento da temperatura, o material apresentou fratura dúctil, pois houve um aumento na tenacidade do material.

\section{CONCLUSÕES}

O tratamento térmico realizado favoreceu o crescimento dos grãos, aumentando a capacidade de absorção de energia ao impacto do material, quando comparamos a amostra encruada com as recozidas. Quanto maior o 
tempo de recozimento, maior será o tamanho de grão do material. Em contrapartida, quanto maior o tempo de recozimento, menor será a dureza do material.

A amostra que não passou por tratamento térmico de recozimento apresentou uma fratura frágil, que requer uma baixa quantidade de energia para a propagação da trinca, caracterizada por mecanismos de fratura por clivagem e intergranular.

As amostras que passaram pelo tratamento térmico de recozimento apresentaram uma fratura dúctil-frágil, em decorrência do crescimento de grãos de ferrita e perlita, tornando o material mais dúctil. Isso pode ser observado devido o aparecimento de dimples na superfície do material.

Provavelmente, ocorreu a recristalização dos grãos durante o tratamento térmico de recozimento, e em seguida o seu crescimento, o qual não foi suficiente para comprometer a tenacidade ao impacto do material. Não obstante, observou-se o oposto. A recristalização observada promoveu um aumento significativo da tenacidade ao impacto.

\section{REFERÊNCIAS}

[1] AKBARI, E.; KARIMI TAHERI, K.; KARIMI TAHERI, A. The Effect of Prestrain Temperature on Kinetics of Static Recrystallization, Microstructure Evolution, and Mechanical Properties of Low Carbon Steel. Journal of Materials Engineering and Performance, v. 27, n. 5, p. 2049-2059, 2018.

[2] ANDERSON, Ted L. Fracture mechanics: fundamentals and applications. Boca Raton: CRC press; 1995.

[3] ASTM E112-13, Standard Test Methods for Determining Average Grain Size, ASTM International, West Conshohocken, PA, 2013.

[4] ASTM E18-19, Standard Test Methods for Rockwell Hardness of Metallic Materials, ASTM International, West Conshohocken, PA, 2019.

[5] ASTM E23-02, Standard Test Methods for Notched Bar Impact Testing of Metallic Materials, ASTM International, West Conshohocken, PA, 2002.

[6] CALLISTER, William D. Jr. Ciência e Engenharia de Materiais: Uma Introdução. 8. ed. Rio de Janeiro: LTC, 2012.

[7] CHIAVERINI, Vicente. Aços e Ferros fundidos. 7. ed. São Paulo: Associação Brasileira de Metalurgia e Materiais, 1996.

[8] CHIAVERINI, Vicente. Tecnologia Mecânica. Vol. III. 2. ed. São Paulo: McGraw-Hill Ltda., 1986.

[9] D. DONG et al. Microstructure and texture evolution during recrystallization of low-carbon steel sheets. Journal of Iron and Steel Research International, v. 24, n. 1, p. 84-90, 2017.

[10] DIETER, George E. et al. Metalurgia Mecânica. 2 ed. Rio de Janeiro: Guanabara Koogan, 2012.

[11] EMYGDIO, Guilherme Zeemann Pinho. Relação Microestrutura x Tenacidade ao Impacto de Flanges Forjados de Aço C-Mn para Trabalho em Baixas Temperaturas e Efeitos de Tratamentos Térmicos. 2012. $66 \mathrm{f}$. Projeto de Graduação - Universidade Federal do Rio de Janeiro, Rio de Janeiro, 2012.

[12] FREITAS, Bruno M. et. al. Microestrutura e microdureza do aço sae 1020 em diferentes tratamentos térmicos. In: SEMANA OFICIAL DA ENGENHARIA E DA AGRONOMIA, 72., 2016, Foz do Iguaçu. Anais eletrônicos... Foz do Iguaçu: CONTECC, 2016. Disponível em: < http://www.confea.org.br/media/contecc2016/mecanica/microestrutura $\% 20 \mathrm{e} \% 20$ microdureza $\% 20 \mathrm{do} \% 20 \mathrm{a} \% \mathrm{C}$ $3 \%$ A7o\%20sae $\% 201020 \% 20 \mathrm{em} \% 20$ diferentes $\% 20$ tratamentos\%20t\%C3\%A9rmicos.pdf $>$. Acesso em: 30 de jan. 2019.

[13] KUANG, C. FU et al. Effect of Continuous Annealing on Microstructure and Bake Hardening Behavior of Low Carbon Steel. Journal of Iron and Steel Research International, v. 22, n. 2, p. 163-170, 2015.

[14] MAZAHERI, Y. et al. Kinetics of Ferrite Recrystallization and Austenite Formation During Intercritical Annealing of the Cold-Rolled Ferrite/Martensite Duplex Structures. Metallurgical and Materials Transactions A: Physical Metallurgy and Materials Science, v. 47, n. 3, p. 1040-1051, 2016.

[15] PADILHA, Angelo F.; SILICIANO JR, Fulvio. Encruamento, Recristalização, Crescimento de Grão e Textura. 3. ed. São Paulo: Associação Brasileira de Metalurgia e Materiais, 2005.

[16] PEREIRA, José M., FRAGA, Francisco E., COSTA, Ycaro J. Influência da Temperatura e do Tamanho de Grão Sobre a Tenacidade à Fratura de um Aço Baixo Carbono. In: SEMANA OFICIAL DA ENGENHARIA E DA AGRONOMIA, 72., 2015, Fortaleza. Anais eletrônicos... Fortaleza: CONTECC, 2015. Disponível em: <http://www.confea.org.br/media/Agronomia_influencia_da_temperatura_e_do_tamanho_de_grao_sobre_a_t enacidade_a_fratura_de_um_aco_baixo_carbono.pdf >. Acesso em: 25 de jan. 2019. 
[17] REVISTA MATÉRIA. Tenacidade à Fratura e Propagação de Trinca de Fadiga de uma Superliga INCONEL 600. Rio de Janeiro, v. 9, n. 4, pp. 315-324, 2004.

[18] REVISTA MILITAR DE CIÊNCIA E TECNOLOGIA. Caracterização de fraturas frágil e dúctil em microscopia eletrônica de varredura (MEV). Rio de Janeiro, v. 34, n. 3, pp. 5-7, 2017.

[19] RODRIGUES, Luciano M. et al, Estudo da microestrutura e da microdureza dos aços 1020 e 1060 . Edição Especial do Curso de Mestrado Profissional em Materiais da UniFOA, 2014.

[20] SILVA, André L.; MEI, Paulo R. Aços e Ligas Especiais. 2 ed. São Paulo: Eletrometal S.A. Metais Especiais, 1988.

[21] TEWARY, N. K. et al. Influence of cold rolling on microstructure, texture and mechanical properties of low carbon high Mn TWIP steel. Materials Science and Engineering A, v. 615, p. 405-415, 2014.

[22] VOORT, George F. Visual examination and light microscopy. In: ASM Handbook: Fractography. USA: ASM International, 1992. v. 12.

[23] YANG, K. et al. Microstructures and fracture features of cold-rolled low carbon steel sheet after annealing and mechanical stress concurrently loaded. Materials Science and Engineering A, v. 502, n. 1-2, p. 126-130, 2009. 